\title{
Karakterisasi Paparan Long Term Particulate Matter di Puspiptek Serpong-Kota Tangerang Selatan
}

\section{Characterization of Long Term Exposure of Particulate Matter at Puspiptek Serpong-South Tangerang}

\author{
Leons Rixson ${ }^{1}$, Etty Riani ${ }^{2}$ dan Muhayatun Santoso ${ }^{3}$ \\ ${ }^{1}$ Sekolah Pascasarjana, Fakultas Multidisplin, Institut Pertanian Bogor, Bogor \\ ${ }^{2}$ Fakultas Ilmu Perikanan dan kelautan, Institut Pertanian Bogor, Bogor \\ ${ }^{3}$ Pusat Sains dan Teknologi Nuklir Terapan, BATAN \\ Jl. Tamansari 71, Bandung 40132, Indonesia \\ Email : leons@batan.go.id
}

Diterima 24-03-2015; Diterima dengan revisi 16-04-2015; Disetujui 26-05-2015

\begin{abstract}
ABSTRAK
Karakterisasi Paparan Long Term Particulate Matter di Puspiptek Serpong-Kota Tangerang Selatan. Pencemaran partikulat udara $\left(P M_{10}\right.$ dan $\left.P M_{2.5}\right)$ tidak mengenal batas administrasi wilayah hal ini disebabkan bahwa pencemaran udara tidak hanya berasal dari wilayah lokal namun dapat bertransportasi dari provinsi maupun negara lain. Unsur sampel partikulat yang dikumpulkan di Serpong, Tangerang Selatan selama 24 jam periode tahun 2011 sampai dengan 2013 diidentifikasikan dengan Spekstroskopi Florensensi Sinar-X (XRF). Karekterisasi faktor dilakukan dengan menggunakan reseptor model positive matrix factorization (PMF) dan perkiraan lokasi sumber pencemar menggunakan metode Conditional Probability Function (CPF). Hasil menunjukkan rentang rata-rata konsentrasi massa $\mathrm{PM}_{2.5}$ adalah $12.63 \pm 1.60$ to $15.89 \pm 1.70 \mu \mathrm{g} / \mathrm{m}^{3}$ sedangkan untuk $P M_{10}$ berkisar $29.00 \pm 3.96$ to $31.04 \pm 3: 28 \mu \mathrm{g} / \mathrm{m}^{3}$. Multi unsur yang teridentifikasi dengan $X R F$ adalah $\mathrm{Al}, \mathrm{Ca}, \mathrm{Co}, \mathrm{Cr}, \mathrm{Cu}$, $\mathrm{Fe}, \mathrm{K}, \mathrm{Mg}, \mathrm{Mn}, \mathrm{Na}, \mathrm{Ni}, \mathrm{Pb}, \mathrm{S}, \mathrm{Si}, \mathrm{Ti}, \mathrm{V}$ dan $\mathrm{Zn}$. Karakterisasi partikulat halus $\left(P M_{2.5}\right)$ teridentifikasi 5 faktor yaitu industri peleburan logam $\mathrm{Pb}$ (9.61\%), debu tanah (17\%), campuran industri peleburan logam dan garam laut $(13.02 \%)$, trasnportasi $(44.36 \%)$ serta pembakaran biomassa $(22.58 \%)$.
\end{abstract}

Kata kunci : polusi udara, spektroskopi XRF, sumber pembagian, fungsi probabilitas bersyarat

\begin{abstract}
Characterization of Long Term Exposure of Particulate Matter at Puspiptek Serpong-South Tangerang. Particulate air pollution $\left(\mathrm{PM}_{10}\right.$ and $\left.\mathrm{PM}_{2.5}\right)$ has no administrative borders due to the foot that air pollution is not only derived from the local area but can be transported from other provinces or countries area. Elements of particulate samples that were collected at Serpong, Tangerang Selatan during the 24-hours sampling from 2011 to 2013 period were inditified by X-Ray Fluorescence Spectroscopy (XRF). The characterization factor was analyzed using receptor model positive matrix factorization (PMF) and the estimation of source location using Conditional Probability Function $(\mathrm{CPF})$ method. The results showed that the average range of $\mathrm{PM}_{2.5}$ mass concentration is $12.63 \pm 1.60$ to $15.89 \pm 1.70 \mu \mathrm{g} / \mathrm{m}^{3}$ while for $\mathrm{PM}_{10}$ it is, $29.00 \pm 3.96$ to $31.04 \pm 3: 28 \mu \mathrm{g} / \mathrm{m}^{3}$. Inditified elements were $\mathrm{Al}, \mathrm{Ca}, \mathrm{Co}, \mathrm{Cr}, \mathrm{Cu}$, $\mathrm{Fe}, \mathrm{K}, \mathrm{Mg}, \mathrm{Mn}, \mathrm{Na}, \mathrm{Ni}, \mathrm{Pb}, \mathrm{S}, \mathrm{Si}, \mathrm{Ti}, \mathrm{V}$ and $\mathrm{Zn}$. The fine particulate $\left(\mathrm{PM}_{2.5}\right)$ source was identified into 5 factors, i.e., metal smelter industry $(9.61 \%)$, dust soil $(17 \%)$, mix of metal smelter industry and transportation $(13.02 \%)$, transportation $(44.36 \%)$ and biomass burning $(22.58 \%)$.
\end{abstract}

Key word : air pollution, XRF spectroscopy, source apportionment, conditional probability function 


\section{PENDAHULUAN}

Pertumbuhan populasi penduduk yang tinggi di Tangerang Selatan dengan aktivitas yang beragam mulai dari sektor pertanian, perkebunan, industri, perumahan dan transportasi mengakibatkan peningkatan polutan antropogenik yang juga mengakibatkan penurunan daya dukung lingkungan dan pada akhirnya dapat menimbulkan penyakit yang berhubungan dengan saluran pernafasan. Perubahan kualitas udara dapat terjadi secara fisis maupun kimiawi seperti pengurangan maupun penambahan konsentrasi salah satu komponen yang juga disebut dengan pencemaran udara. Pencemaran lingkungan udara merupakan pencemaran yang tidak mengenal batas administrasi wilayah. Pencemaran udara di suatu wilayah tidak hanya berasal dari sumber pencemar lokal namun dapat pula berasal dari transportasi lintas provinsi maupun negara. Particulate Matter $(P M)$ merupakan salah satu dari 12 parameter pencemar udara yang terdapat di dalam PP No 41 tahun 1999 tentunya $P M$ ini memiliki dampak paling berbahaya bagi kesehatan manusia karena kemampuannya yang dapat masuk sampai ke sistem pernapasan yang paling dalam. Partikel berukuran $2.5 \mu \mathrm{m}$ sampai dengan $10 \mu \mathrm{m}$ $\left(P M_{2.5^{-10}}\right)$ dapat menembus ke dalam paru tanpa tersaring oleh rambut di dalam hidung. Partikel berukuran dibawah $2.5 \mu \mathrm{m}$ $\left(P M_{2,5}\right)$ apabila terhirup tidak dapat disaring dalam sistem pernapasan bagian atas dan akan menembus bagian terdalam paru-paru [1]. Dampak paparan jangka pendek (short term) maupun jangka panjang (long term) dari PM menimbulkan bahaya bagi kesehatan manusia. Hal tersebut menjadialasan utama kenapa pemantauan kualitas udara parameter $P M$ perlu dilakukan. Salah satu studi menyatakan bahwa paparan long term $P M_{10}$ secara signifikan akan menghambat pertumbuhan volume paru-paru anak sekolah dasar [2]. Studi multikota yang dilakukan di Eropa (29 kota) dan di Amerika Serikat (20 kota) melaporkan efek mortalitas paparan singkat untuk $P M_{10} \quad 0,62 \%$ dan
$0,46 \%$ per setiap kenaikan $10 \mu \mathrm{g} / \mathrm{m}^{3}$ (24 jam rata-rata) [3]. Studi 24 kota di Harvard, Amerika Serikat menyebutkan efek paparan $P M$ dengan waktu yang lama berakibat terhadap peningkatan terjadinya penyakit saluran pernapasan pada anak-anak [4]. Publikasi WHO memberikan nilai baku mutu konsentrasi massa rata-rata tahunan untuk $P M_{10}$ sebesar $20 \mu \mathrm{g} / \mathrm{m}^{3}$ dan untuk periode $24 \mathrm{jam}$ adalah $50 \mu \mathrm{g} / \mathrm{m}^{3}$ sedangkan rata-rata tahunan $P M_{2.5} 10 \mu \mathrm{g} / \mathrm{m}^{3}$ dan $24 \mathrm{jam}$ adalah $25 \mu \mathrm{g} / \mathrm{m}^{3}$ [5]. Baku mutu udara ambien nasional 24 jam untuk $P M_{10}$ adalah $150 \mu \mathrm{g} / \mathrm{m}^{3}$ sedangkan $P M_{2.5}$ sebesar $65 \mu \mathrm{g} / \mathrm{m}^{3}$ untuk 24 jam dan $15 \mu \mathrm{g} / \mathrm{m}^{3}$ untuk periode 1 tahun [6].

Pemantauan konsentrasi massa dan identifikasi multi unsur $P M$ dapat digunakan sebagai karakterisasi jenis dan estimasi lokasi sumber pencemar sehingga dapat digunakan sebagai dasar acuan pengendalian dan pencegahan pencemaran udara agar tidak melebihi dari nilai baku mutunya. Penelitian mengenai karakterisasi dan identifkasi sumber pencemar $P M$ daerah perkotaan telah dilakukan di beberapa negara termasuk Indonesia. Laporan Europe Environmental Agency (EEA) tahun 2013 menyatakan faktor sumber emisi primer dari total konsentrasi $P M$ untuk wilayah eropa sejak tahun 2002-2011 berasal dari tungku pembakaran perumahan, industri dan institusi pemerintah. Sektor tersebut memberi kontribusi peningkatan dari $33 \%$ hingga $39 \%$ untuk $P M_{10}$ dan $42 \%$ hingga 50 $\%$ pada tahun 2002 hingga 2011 [7]. Kajian kualitas udara di kawasan Asia periode tahun 2002-2005 menyatakan rata-rata konsentrasi massa terendah partikulat kasar dan halus adalah dari Negara New Zealand namun demikian 12 dari 22 negara yang ikut berpartipasi, konsentrasi massa $P M$ kasar dan halus melebihi nilai baku mutu yang ditetapkan WHO [8].

Kajian sebelumnya untuk paparan waktu singkat tahun 2008 menyebutkan bahwa konsentrasi $P M_{2.5}$ wilayah serpong melebihi dari nilai baku rata-rata tahunan sebesar $15 \mu \mathrm{gg} / \mathrm{m}^{3}$. Identifikasi rata-rata konsentrasi $\mathrm{Pb}$ pada kandungan partikulat 
udara $P M_{10}$ dan $P M_{2.5}$ di salah satu kawasan industri wilayah Serpong adalah 1.60 dan $0.63 \mu \mathrm{g} / \mathrm{m}^{3}$ [9]. Hasil pengukuran short term yang dilakukan pada periode tahun 20082010 menyebutkan adanya kenaikan ratarata konsentrasi $P M_{2.5}$ yaitu $15.2 \pm 7 \mu \mathrm{g} / \mathrm{m}^{3}$ $20.6 \pm 6 \mu \mathrm{g} / \mathrm{m}^{3}$ sedangkan $P M_{10} 31.17 \pm$ $13.7 \mu \mathrm{g} / \mathrm{m}^{3}-34.17 \pm 7.2-20.6 \mu \mathrm{g} / \mathrm{m}^{3}$ [10]. Tujuan dilakukannya penelitian ini adalah untuk menganalisis partikulat udara $\left(P M_{10}\right.$ dan $P M_{2.5}$ ) paparan waktu lama yang terdiri dari; analisis konsentrasi partikulat, identifikasi unsur partikulat, karakteriasasi tipe asal sumber pencemar partikulat udara, serta perkiraan lokasi sumber pencemar udara.

\section{BAHAN DAN METODE}

\section{Sampling dan data}

Sampel partikulat udara dicuplik dengan Gent Stacked Filter Unit Sampler selama 24 jam dengan laju alir $18 \mathrm{l} / \mathrm{min}$. Sampling dilakukan pada rentang waktu 2011-2013. Lokasi sampling berada di kawasan Pusat Ilmu Pengetahuan dan Teknologi (PUSPIPTEK) Serpong, Kota Tangerang Selatan. Wilayah kajian penelitian meliputi Kota Tangerang Selatan, Kecamatan Bogor Barat, Kabupaten Tangerang dan Jakarta Selatan. Lokasi penelitian dilakukan di Pusat Sains Teknologi Nuklir Terapan-Badan Tenaga Nuklir Nasional (PSTNT-BATAN) Bandung, Jawa Barat.

Data yang digunakan dalam kajian ini adalah data sekunder yang terdiri dari data Konsentrasi massa $P M$, Black Carbon $(B C)$, serta identifikasi unsur $P M_{2.5}$ periode 20112013 yang diperoleh dari PSTNT-BATAN Bandung. Data meteorologi berupa arah dan kecepatan angin tahun 2013 yang diperoleh dari BMKG pada stasiun meteorologi Budiarto Curug, Tangerang diperlukan untuk estimasi lokasi sumber pencemar.

\section{Konsentrasi massa partikulat $(P M)$ dan karbon hitam $(B C)$}

Nilai konsentrasi massa $P M_{2.5}$ dan $P M_{10}$ diukur menggunakan metode gravimetri. Persamaan yang digunakan adalah seperti persamaan 1 dan 2. $M_{1}(\mu \mathrm{g})$ adalah massa bersih $P M_{2.5}$ sebelum dan setelah sampling dan $V_{1}\left(\mathrm{~m}^{3}\right)$ adalah volume udara sampel.

$$
\begin{aligned}
P M_{2.5} & =\frac{\mathrm{M}_{1}}{\mathrm{~V}_{1}}\left(\mu \frac{\mathrm{g}}{\mathrm{m}^{3}}\right) \\
P M_{10} & =P M_{2.5}+P M_{2.5-10}
\end{aligned}
$$

Analisis $B C$ menggunakan prinsip reflektansi cahaya dengan alat smokestain reflectometer. Cahaya yang berasal dari suatu sumber cahaya/lampu dihamburkan melalui annular photocell ke permukaan filter sampel, selanjutnya cahaya tersebut direfleksikan kembali ke photocell. Cahaya yang direfleksikan atau diserap pada filter sampel bergantung pada konsentrasi partikel, densitas, refraksi indeks dan ukuran. Nilai reflektans yang diperoleh dari filter sampel merupakan nilai yang sebanding dengan jumlah $B C$ pada filter. Persamaan untuk mengukur $B C$ terlihat pada persamaan 3 . dengan A adalah luas sampel $\left(\mathrm{cm}^{2}\right), \mathrm{V}$ adalah volume sampel $\left(\mathrm{m}^{3}\right), \quad \mathrm{R}_{0}$ adalah nilai reflektans dari filter blangko $(100 \%)$ dan $R$ adalah nilai reflektans dari filter sampel $(\%)$, nilai konstanta $\varepsilon$ adalah $5.27 \mathrm{~m}^{2} / \mathrm{g}$.

$$
B C=\left(\mu \frac{\mathrm{g}}{\mathrm{m}^{3}}\right)=\frac{\mathrm{A}}{\mathrm{V}} \times\left\{\frac{100}{2 \varepsilon}\right\} \operatorname{Ln}\left\{\frac{\mathrm{R}_{0}}{\mathrm{R}}\right\}
$$

Konsentrasi massa $P M_{2.5}, P M_{10}, B C$ dipisahkan berdasarkan tahun periode dan selanjutnya dianalisis secara deskriptif untuk mendapatkan trend konsentrasi massa setiap tahun periode, rasio dan korelasi $P M_{2.5}$ terhadap $P M_{10}$ serta rasio $B C$ terhadap $P M_{2.5}$. Uji-t digunakan sebagai pembanding terhadap nilai baku mutu, uji Anova dan Post Hoc Multiple Comparisson untuk analisis perbedaan konsentrasi rata-rata berdasarkan tahun. 


\section{Identifikasi multi unsur}

Identifikasi multi unsur dilakukan dengan menggunakan spektroskopi X-Ray Fluorescence $(X R F)$ Epsilon 5. Prinsip analisis spektrometer $X R F$ adalah dengan memanfaatkan pancaran emisi radiasi dari sinar-X karakterisitik sekunder yang menjadi ciri setiap unsur dari suatu bahan. Sinar-X karakteristik sekunder dihasilkan dari proses tereksitasi atau terioniasinya elektron kulit terdalam akibat pancaran emisi radiasi sinar-X primer pada energi tertentu terhadap target yang disebut efek fotolistrik. Radiasi sinar-X sekunder selanjutnya dideteksi oleh detektor sinar-X menjadi pulsa-pulsa listrik. Pulsa tersebut diperkuat oleh penguat awal dan penguat akhir. Pulsa listrik yang telah diperkuat oleh penguat akhir digunakan sebagai inputbagi Analog to Digital Converter (ADC) untuk diubah menjadi bilangan digital dan selanjutnya diolah komputer menjadi luasan spektrum hasil yang akan dianalisis secara qualitatif maupun quantitatif.

Kualitatif unsur dilakukan dengan mencocokkan puncak intensitas tertinggi sampel pada energi tertentu dengan tabel referensi yang memuat daftar energi yang berbasis unsur. Konsentrasi unsur $P M$ dengan analisis kuantitatif dilakukan dengan terlebih dahulu membuat kurva kalibrasi unsur standar sehingga didapatkan fungsi linear $Y=A x+B$ antara energi $(\mathrm{KeV})$ terhadap intensitas konsentrasi unsur $\left(\mu \mathrm{g} / \mathrm{cm}^{2}\right)$.

Data konsentrasi multi unsur yang didapatkan kemudian direkonstruksi dengan teknik Reconstructed Concentration Mass $(R C M)$. Perhitungan nilai $R C M$ dilakukan untuk mendapatkan nilai penjumlahan konsentrasi massa $B C$ beserta unsur-unsur penyusun utama $P M_{2.5}$ yang terdeteksi pada sampel. Selanjutnya nilai RCM tersebut dibandingkan melalui uji regresi untuk mendapatkan proporsi konsentrasi massa RCM terhadap hasil pengukuran konsentrasi massa $P M_{2.5}$ melalui metode gravimetri [11]. Lima komponen utama pembentuk $P M_{2.5}$ adalah $B C$, materi organik (OM), sulfat, garam laut, debu tanah, dan asap.
Persamaan yang diberikan adalah sebagai berikut;

$\mathrm{RCM}=$ Sulfat + Garam Laut +

Asap + Debu Tanah $+B C+\mathrm{OM}$

\begin{tabular}{|c|c|}
\hline Sulfat & $=4.125 \times \mathrm{X} \mathrm{S}$ \\
\hline Garam Laut & $=2.54 \times \mathrm{Na}$ \\
\hline Asap & $=\mathrm{K}-0.6 \times \mathrm{Fe}$ \\
\hline Debu Tanah & $\begin{aligned}= & 2.2 \mathrm{Al}+2.49 \mathrm{Si}+ \\
& 1.63 \mathrm{Ca}+1.94 \mathrm{Ti}+ \\
& 2.42 \mathrm{Fe}\end{aligned}$ \\
\hline
\end{tabular}

Unsur-unsur minor $= \pm 2 \%$

Reseptor model positive matrix factorization (PMF)

Data konsentrasi massa yang telah dianalisis selanjutnya dikarakterisasi dan dikuantifikasi jenis faktor sumber pencemar dengan reseptor modeling PMF melalui korelasi berbagai unsur sebagai unsur penanda sumber pencemar. $P M F$ adalah metode berbasis analisis multi variate yang menghasilkan informasi mengenai keberadaan, kekuatan, distribusi dan prilaku kejadian tiap unsur yang terdapat dalam sampel $P M$ [12].

Jumlah data dan unsur yang teridentifikasi tersusun dalam sebuah matriks $\mathrm{X}$ dengan dimensi baris adalah jumlah data sampel (i) sedangkan dimensi kolom adalah jumlah unsur yang teridentifikasi dalam sampel (j). Matriks X tersebut difaktorisasi dalam dua bentuk yaitu $G(\mathrm{ik})$ dan $F(\mathrm{kj})$. Xij adalah konsentrasi spesies j ( $\mu \mathrm{g} / \mathrm{m} 3)$ diukur dalam sampel i, $G_{i k}$ adalah matriks kontribusi sumber yaitu konsentrasi massa $(\mu \mathrm{g} / \mathrm{m} 3)$ dari sumber $\mathrm{k}$ yang berkontribusi terhadap sampel $i$, dan $f_{k j}$ adalah matriks komposisi fraksi massa spesies $\mathrm{j}(\mu \mathrm{g} / \mathrm{m} 3)$ dari sumber $\mathrm{k}$. $\mathrm{e}_{\mathrm{ij}}$ adalah residu konsentrasi spesies $\mathrm{j}$ terukur pada sampel i yang dihitung dengan menggunakan persamaan 5 .

$$
\begin{aligned}
& x_{i j}=\sum_{k=1}^{p} G_{i k} F_{k j}+e_{i j} \\
& e_{i j}=X_{i j}-\sum_{k=1}^{p} G_{i k} F_{k j}
\end{aligned}
$$


Hasil yang diperoleh diupayakan tidak ada sampel yang memiliki kontribusi sumber yang bernilai negatif, hal ini dilakukan dengan cara meminimalisasi jumlah kuadrat residual dengan estimasi error pada setiap data $Q$, sebagai berikut.

$$
Q=\sum_{i=1}^{n} \sum_{j=1}^{m}\left(\frac{\left[X_{i j}-\sum_{k=1}^{p} G_{i k} F_{k j}\right]}{u_{i j}}\right)^{2}
$$

\section{Estimasi lokasi dengan conditional probalitiy function (CPF)}

Estimasi lokasi sumber pencemar lokal dilakukan dengan cara menggabungkan data konsentrasi unsur terhadap data meteorologi arah dan kecepatan angin. Analisis kedua data tersebut menggunakan metode $C P F$ dengan bantuan perangkat lunak microsoft excel. Metode $C P F$ adalah membagi jumlah kejadian pada arah angin tertentu $\left(\mathrm{M}_{\Delta \theta}\right)$ dengan kontribusi $25 \%$ konsentrasi massa terbesar faktor denganarah dan kecepatan angin diatas $1 \mathrm{~m} / \mathrm{s}$ terhadap total konsentrasi massa faktorpada arah $\left(\mathrm{n}_{\Delta \theta}\right)$ dan kecepatan angin yang lebih besardari $1 \mathrm{~m} / \mathrm{s}$ seperti pada persamaan 8. Hasil analisis CPFdi bentuk dalam plotradar kemudian di overlay kedalam peta lokasi titik sampling.

$$
C P F_{\Delta \theta}=\frac{\mathrm{M}_{\Delta \theta}}{\mathrm{n}_{\Delta \theta}}
$$

\section{HASIL DAN PEMBAHASAN}

\section{Pola distribusi konsentrasi massa particulate matter (PM)}

Secara deskriptif konsentrasi $P M_{2.5}$ dan $P M_{10}$ selama kurun waktu tiga tahun periode 2011-2013 terlihat seperti pada Tabel 1. Konsentrasi massa rata-rata $P M_{2.5}$ berturutturut untuk tahun 2011-2013 adalah $15.89 \pm$ $1.70,12.63 \pm 1.60$ dan $12.66 \pm 1.74 \mu \mathrm{g} / \mathrm{m}^{3}$. Sedangkan rata-rata konsentrasi $P M_{10}$ berturut-turut $31.04 \pm 3.28,29.00 \pm 3.96$ dan $29.00 \pm 3.72 \mu \mathrm{g} / \mathrm{m}^{3}$. Gambar 1 memperlihatkan pola konsentrasi massa $P M$ yang cenderung serupa dari waktu ke waktu namun terjadi penurunan rata-rata konsentrasi massa sebesar $21 \%$ dibandingkan pada tahun 2011 dan 2012. Berdasarkan nilai rata-rata konsentrasi massa $P M_{2.5}$ tersebut, apabila dibandingkan dengan baku mutunya dalam PP no 41 tahun 1999 sebesar $15 \mu \mathrm{g} / \mathrm{m}^{3}$ hanya konsentrasi $P M_{2.5}$ pada tahun 2011 yang berada di atas nilai baku mutu tahunan namun dari seluruh nilai konsentrasi massa rata-rata baik itu untuk $P M_{2.5}$ maupun $P M_{10}$ pada periode tiga tahun tersebut tidak ada yang melebihi nilai baku mutu konsentrasi rata-rata 24 jam $P M_{2.5}$ dan $P M_{10}$ yaitu 65 $\mu \mathrm{g} / \mathrm{m}^{3}$ dan $150 \mu \mathrm{g} / \mathrm{m}^{3}$.

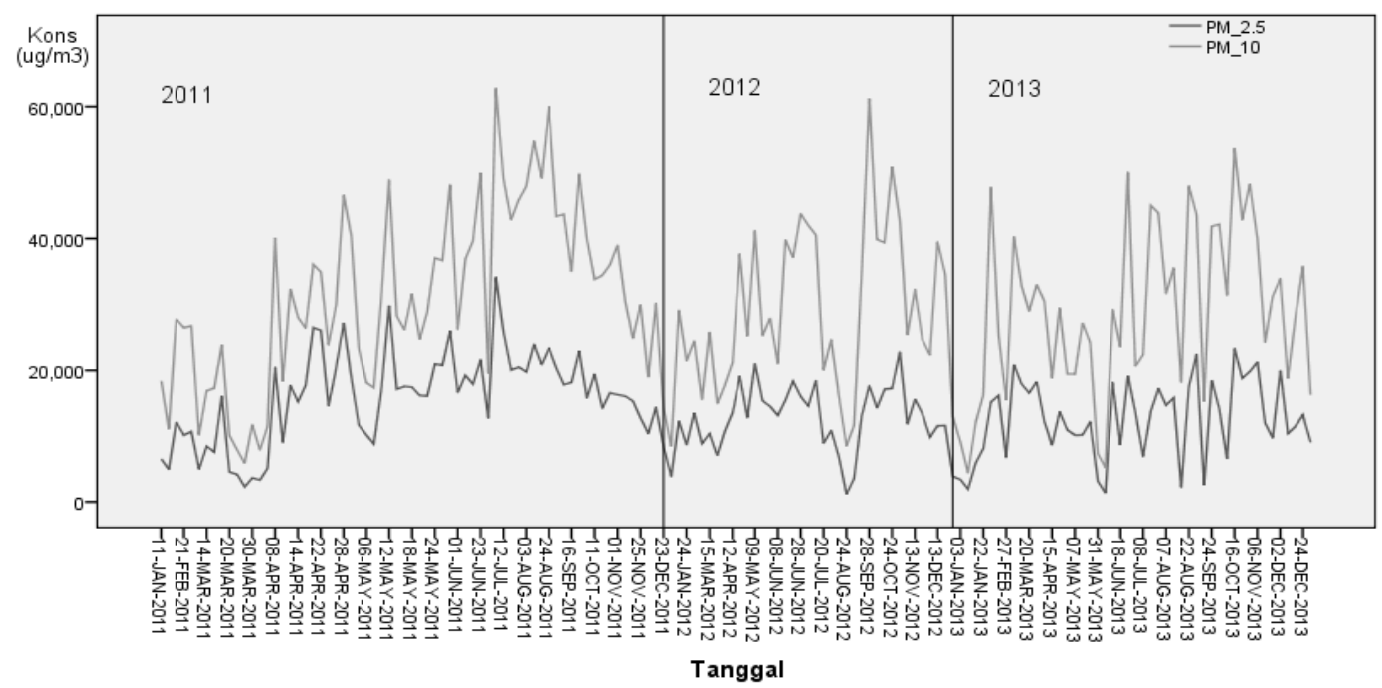

Gambar 1. Trend Konsentrasi Massa PM 2011-2013 
Berdasarkan Tabel 1 konsentrasi massa $P M_{2.5}$ tahun 2011 lebih tinggi dari nilai baku tahunan oleh karena itu Uji-t dilakukan untuk membuktikan apakah nilai konsentrasi rata-rata $P M_{2.5}$ tahun 2011 secara signifikan berada diatas nilai baku mutunya. Hasil yang didapat adalah nilai t hitung lebih kecil dari nilai t-tabel, maka tidak benar nilai konsentrasi $P M_{2.5}$ pada tahun 2011 lebih besar dari nilai baku mutunya. Terlihat pula pada Tabel 1 nilai rerata $P M_{2.5}$ dan $P M_{10}$ pada tahun 2011 lebih tinggi dibandingkan tahun 2012 dan tahun 2013 sehingga dilakukan Uji Anova dan Post Hoc Multiple Comparisson, hasil uji Anova yang didapat adalah ada perbedaan konsentrasi massa yang signifikan data ketiga tahun tersebut sedangkan uji Post Hoc Multiple Comparisson pada Tabel 2 menghasilkan perbedaan signifikan tahun tersebut adalah antara tahun 2011 terhadap 2012 dan 2013.

Konsentrasi rata-rata pada periode tahun 2011-2013 Apabila dibandingkan dengan hasil paparan jangka pendek yang sebelumnya pernah dilakukan pada bulan
Agustus sampai dengan Desember tahun 2008 di Kawasan Puspiptek Serpong yang memberikan nilai konsentrasi $P M_{2.5}$ sebesar $20.2 \mathrm{\mu g} / \mathrm{m}^{3}$ sedangkan $P M_{10}$ sebesar 39.9 $\mu \mathrm{g} / \mathrm{m}^{3}$ [9] maka pengukuran $P M$ periode tahun 2011-2013 memberi perbedaan hasil konsentrasi yang lebih rendah yaitu sebesar $30.3 \%$ untuk $P M_{2.5}$ dan $25 \%$ untuk $P M_{10}$. Perbandingan konsentrasi massa selama rentang periode pengukuran $P M_{2.5}$ terhadap $P M_{10}$ memberi makna persentase kontribusi $P M_{2.5}$ didalam $P M_{10}$. Berdasarkan Tabel 3 persentase rasio konsentrasi emisi partikulat halus $\left(P M_{2.5}\right)$ dan kasar $\left(P M_{10}\right)$ pada periode tahun 2011-2013 udara di Kota Tangerang Selatan berkisar diantara 43.55-51.20\%. Nilai kontribusi $P M_{2.5}$ terhadap $P M_{10}$ sebanding dengan hasil studi yang dilakukan pada tahun 2008 di Serpong pada enam lokasi sampling dimana nilai kontribusi yang didapat sebesar 31-51\% [9].

Penurunan konsentrasi $P M_{2.5}$ dari tahun 2011-2013 dapat disebabkan durasi musim kering yang lebih tinggi dibandingkan dengan musim basah (hujan). Hal ini mengakibatkan tingginya konsentrasi

Tabel 1. Analisa deskriptif konsentrasi $P M$

\begin{tabular}{ccccccc}
\hline$P M$ & Tahun & $\mathrm{N}$ & $\begin{array}{c}\text { rata-rata } \\
\left(\mu \mathrm{g} / \mathrm{m}^{3}\right)\end{array}$ & $\begin{array}{c}\text { Std. Error }(95 \% \\
\text { Conf.Lev })\end{array}$ & \multicolumn{2}{c}{ Uji-t (t-value $=15)$} \\
\hline$P M_{2.5}$ & 2011 & 67 & 15,89 & 1,70 & 1,043 & 1,995 \\
& 2012 & 38 & 12,63 & 1,60 & $-2,974$ & 2,019 \\
& 2013 & 47 & 12,66 & 1,74 & $-2,689$ & 2,016 \\
$P M_{10}$ & Total & 152 & 14,07 & 1,04 & $\mathrm{x}$ & $\mathrm{x}$ \\
& 2011 & 67 & 31,04 & 3,28 & $\mathrm{x}$ & $\mathrm{x}$ \\
& 2012 & 38 & 29,00 & 3,96 & $\mathrm{x}$ & $\mathrm{x}$ \\
& 2013 & 47 & 29,00 & 3,72 & $\mathrm{x}$ & $\mathrm{x}$ \\
& Total & 152 & 29,90 & 2,10 & $\mathrm{x}$ & $\mathrm{x}$ \\
\hline
\end{tabular}

Tabel 2. Uji Post Hoc Multiple Comparisson

\begin{tabular}{|c|c|c|c|c|c|}
\hline Variabel & & (I) tahun & (J) tahun & Beda rata-rata (I-J) & Std. Error \\
\hline \multirow{6}{*}{$P M_{2.5}$} & LSD & 2011 & 2012 & $3,26^{*}$ & 1,26 \\
\hline & & & 2013 & $3,22^{*}$ & 1,18 \\
\hline & & 2012 & 2011 & $-3,26^{*}$ & 1,26 \\
\hline & & & 2013 & $-0,04$ & 1,35 \\
\hline & & 2013 & 2011 & $-3,22^{*}$ & 1,18 \\
\hline & & & 2012 & 0,04 & 1,35 \\
\hline
\end{tabular}


Tabel 3. Persentase kontribusi $P M_{2.5}$ terhadap $P M_{10}$

\begin{tabular}{ccccc}
\hline Tahun & $\mathrm{N}$ & Rerata $P M_{2.5}\left(\mu \mathrm{g} / \mathrm{m}^{3}\right)$ & Rerata $P M_{10}\left(\mu \mathrm{g} / \mathrm{m}^{3}\right)$ & Rasio $P M_{2.5} / P M_{10}(\%)$ \\
\hline 2011 & 67 & 15,89 & 31,04 & 51,20 \\
2012 & 38 & 12,63 & 29,00 & 43,55 \\
2103 & 47 & 12,66 & 29,00 & 43,65 \\
Total & 152 & 14,07 & 29,90 & 47,00 \\
\hline
\end{tabular}

partikulat udara yang melayang di udara. Tabel 4 menunjukan jumlah musim kering dan basah setiap bulannya sejak periode tahun 2011-2013.Musim basah ditandai dengan curah hujan yang melebihi dari 150 $\mathrm{mm}$ setiap bulannya. Selain itu, upaya Pemerintah Kota Tangerang Selatan dalam penanganan sampah sejak tahun 2009 dengan melakukan pembangunan fasilitas Tempat Penampungan Sampah Terpadu Reduce, Recycle, and Reuse (TPST 3R) di tingkat kelurahan ataupun desa dapat meminimalkan pembakaran sampah secara terbuka. Kebijakan pemerintah pusat dalam upaya mengurangi emisi kendaraan bermotor sejak tahun 2006-2012 turut ambil bagian terhadap penurunan konsentrasi $P M$ Kota Tangerang Selatan.

Untuk mengetahui realibilitas data konsentrasi $P M_{2.5}$ terhadap $P M_{10}$ maka dibuat korelasi antar keduanya. Nilai koefisien deteminasi $\left(\mathrm{r}^{2}\right)$ memberi makna persentase pengaruh konsentrasi massa $P M_{2.5}$ terhadap $P M_{10}$. Pola hubungan antar keduanya merupakan akar dari nilai $\mathrm{r}^{2}$. Pada Gambar 2 terlihat nilai $P M_{10} \quad 74.05 \%$ dipengaruhi perubahan variabel konsentrasi massa $P M_{2.5}$ sedangkan $25.95 \%$ dipengaruhi oleh variabel lain. Sedangkan pola hubungan keduanya adalah erat karena nilai koefisien korelasi yang didapat adalah 0.86 .

\section{Analisis multi unsur partikulat halus $\left(\boldsymbol{P} M_{2.5}\right)$}

Unsur-unsur yang teridentifikasi spektroskopi $X R F$ baik untuk fraksi partikel halus $P M_{2.5}$ dan fraksi partikel kasar $P M_{2.5^{-} 10}$ adalah $\mathrm{Na}, \mathrm{Mg}, \mathrm{Al}, \mathrm{Si}, \mathrm{S}, \mathrm{K}, \mathrm{Ca}, \mathrm{Ti}, \mathrm{V}, \mathrm{Cr}$, $\mathrm{Mn}, \mathrm{Fe}, \mathrm{Co}, \mathrm{Ni}, \mathrm{Cu}, \mathrm{Zn}$ dan Pb.Gambar 3 (b)box and whisker plotmenggambarkan sebaran data dari masing-masing unsur. Kotak tersebut menggambarkan rentang quartil 1 terhadap quartil 3, garis horizontal merupakan nilai tengah data, sampel

Tabel 4. Curah hujan Kota Tangerang Selatan Periode 2011-2013 (sumber: BMKG Pondok Betung, Ciputat)

\begin{tabular}{lcccccc}
\hline & \multicolumn{2}{c}{$\mathbf{2 0 1 1}$} & \multicolumn{2}{c}{$\mathbf{2 0 1 2}$} & \multicolumn{2}{c}{$\mathbf{2 0 1 3}$} \\
\cline { 2 - 7 } Bulan & $\begin{array}{c}\text { Curah Hujan } \\
(\mathrm{mm})\end{array}$ & $\begin{array}{c}\text { Hari } \\
\text { hujan }\end{array}$ & $\begin{array}{c}\text { Curah } \\
\text { Hujan } \\
(\mathrm{mm})\end{array}$ & $\begin{array}{c}\text { hari } \\
\text { hujan }\end{array}$ & $\begin{array}{c}\text { Curah } \\
\text { Hujan } \\
(\mathrm{mm})\end{array}$ & $\begin{array}{c}\text { Hari } \\
\text { hujan }\end{array}$ \\
\hline Jan & $\mathbf{1 7 0 , 8}$ & 21 & $\mathbf{4 3 0 , 7}$ & 28 & $\mathbf{5 2 6 , 8}$ & 25 \\
Feb & 132 & 17 & $\mathbf{2 5 8 , 1}$ & 20 & $\mathbf{2 2 4 , 8}$ & 19 \\
Mar & 64 & 18 & $\mathbf{1 3 3 , 3}$ & 17 & 105,6 & 16 \\
Apr & $\mathbf{1 8 6 , 2}$ & 15 & $\mathbf{2 7 7 , 4}$ & 18 & $\mathbf{3 3 6 , 9}$ & 19 \\
May & 122,6 & 20 & $\mathbf{1 9 9 , 1}$ & 20 & $\mathbf{2 2 7 , 2}$ & 16 \\
Jun & 75,5 & 6 & 89,1 & 5 & 82,7 & 14 \\
Jul & 71,8 & 12 & 7,3 & 1 & 348,8 & 22 \\
Aug & 0 & 0 & 9,3 & 2 & 81,6 & 5 \\
Sep & 53,1 & 7 & 12,4 & 4 & 34,8 & 6 \\
Oct & 49,3 & 7 & 89,5 & 8 & 133,5 & 15 \\
Nov & 71,7 & 14 & $\mathbf{3 6 8 , 4}$ & 23 & $\mathbf{2 6 1 , 6}$ & 14 \\
Dec & 83,5 & 14 & $\mathbf{3 2 0 , 4}$ & 20 & $\mathbf{3 4 6 , 2}$ & 25 \\
\hline
\end{tabular}




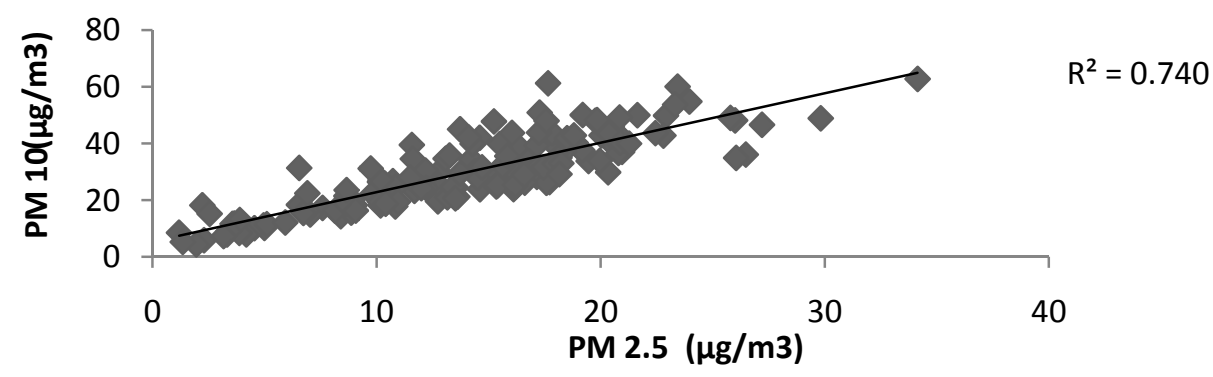

Gambar 2. Korelasi $P M_{2.5}$ terhadap $P M_{10}$ tahun 2011-2013

ekstrim dilambangkan dengan (o) Partikulat primer pada umumnya berasal sedangakan sampel dengan pencilan dari emisi langsung pertikel debu tanah dan dilambangkan $(*)$. garam laut sedangkan partikulat sekunder

\begin{tabular}{ccc}
\hline \multirow{2}{*}{ Unsur } & \multicolumn{2}{c}{ Rata-rata $\left(\mathrm{ng} / \mathrm{m}^{3}\right)$} \\
\cline { 2 - 3 } & Statistik & Std. Error \\
\hline $\mathrm{Na}$ & 117,80 & 9,68 \\
$\mathrm{Mg}$ & 28,72 & 3,36 \\
$\mathrm{Al}$ & 47,57 & 5,70 \\
$\mathrm{Si}$ & 98,42 & 11,74 \\
$\mathrm{~S}$ & 470,34 & 41,29 \\
$\mathrm{~K}$ & 126,45 & 8,89 \\
$\mathrm{Ca}$ & 37,40 & 3,58 \\
$\mathrm{Ti}$ & 2,93 & 0,33 \\
$\mathrm{~V}$ & 0,72 & 0,10 \\
$\mathrm{Cr}$ & 2,01 & 0,19 \\
$\mathrm{Fe}$ & 37,77 & 3,60 \\
$\mathrm{Mn}$ & 3,65 & 0,47 \\
$\mathrm{Co}$ & 0,93 & 0,09 \\
$\mathrm{Ni}$ & 0,56 & 0,06 \\
$\mathrm{Cu}$ & 2,26 & 0,24 \\
$\mathrm{Zn}$ & 75,72 & 6,78 \\
$\mathrm{~Pb}$ & 214,82 & 34,89 \\
\hline
\end{tabular}

(a)

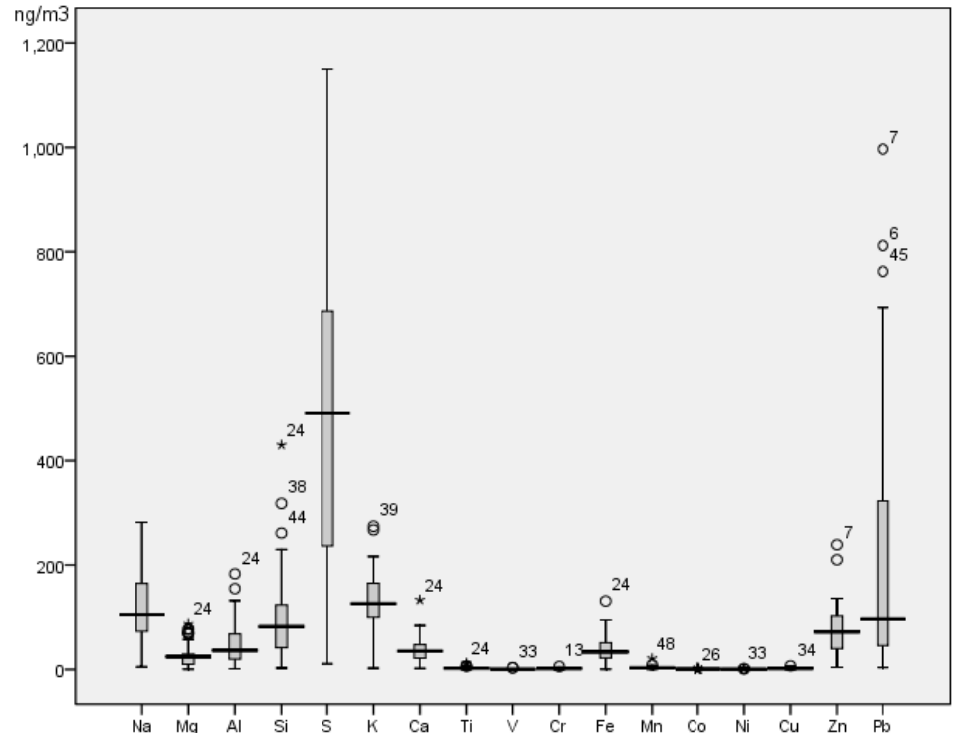

(b)

Gambar 3. Konsentrasi massa (a) serta Box and whisker plot tiap unsur (b)

Terlihat pada Gambar 3 (a) konsentrasi massa rata-rata sulfur (S) lebih tinggi dibandingkan dengan nilai unsur lainnya. Tingginya kandungan sulfur didalam $P M$ dapat dimungkinkan berasal dari emisi kendaraan bermotor. Penelitian yang telah dilakukan di berbagai tempat, menyimpulkan bahwa sumber emisi parikel halus berdasarkan carateremisi ke udara terbagi atas pertikulat primer dan sekunder. didominasi berasal dari emisi transportasiyang banyak mengandung sulfur (S) lalu bertransformasi di atmosfer dalam bentuk $\mathrm{NH}_{4} \mathrm{SO}_{4}$ [13]. Kajian yang dilakukan Khillare pada tahun 2008-2009 di India menyatakan unsur logam $(\mathrm{Cd}, \mathrm{Cu}, \mathrm{Ni}$ dan $\mathrm{Pb})$ dimungkinkan berasal dari emisi kawasan Industri [14]. 


\section{Analisis black carbon (BC) dan recunstructed mass (RCM)}

Konsentrasi $B C$ selama kurun waktu tiga tahun periode 2011-2013 terlihat seperti pada Tabel 5. Konsentrasi rerata $B C$ berturut-turut untuk tahun 2011-2013 adalah $2.48 \pm 0.19,1.92 \pm 0.25$ dan $2.36 \pm 0.25$ $\mu \mathrm{g} / \mathrm{m}^{3}$. Rasio konsentrasi massa pengukuran $B C$ terhadap $P M_{2.5}$ dalam satuan persen merupakan kontribusi $B C$ didalam $P M_{2.5}$. Berdasarkan Tabel 4 dapat dimaknai bahwa pada periode tahun 2011-2013 persentase rata-rata perbandingan konsentrasi massa $B C$ dalam $P M_{2.5}$ di Kota Tangerang Selatan naik $\pm 1 \%$ setiap tahunnya. Terlihat pada Tabel 4 konsentrasi massa $R C M$ pada tahun 2011-2013 berturut adalah 6.60, 4.92 dan $5.37 \mu \mathrm{g} / \mathrm{m}^{3}$. Nilai $R C M$ pada penelitian ini
Tabel 5 memperlihatkan bahwa hasil kontribusi faktor garam laut, debu tanah dan unsur minor semakin meningkat dari tahun ke tahun hal sebaliknya terjadi pada amonium sulfat $\left(\mathrm{NH}_{4} \mathrm{SO}_{4}\right)$ dan asap yang semakin menurun. Peningkatan unsur minor diduga berkaitan dengan kegiatan industri, faktor debu tanah diduga akibat aktivitas kegiatan tambang pasir dan alih fungsi lahan di Kota Tangerang Selatan. Sedangkan asapdapat dimungkinkan dari proses pembakaran tidak sempurna yang pada umumnya adalah pembakaran yang bersifat terbuka seperti sampah. Hasil uji regresi antara $R C M$ terhadap hasil pengukuran $P M_{2.5}$ tahun 2011-2013 memberikan nilai korelasi (r) yang kuat antar keduanya yaitu 0.88 .

Tabel 5. Komponen penyusun $P M_{2.5}$

\begin{tabular}{lcccccc}
\hline \multirow{2}{*}{ Faktor } & \multicolumn{3}{c}{ Konsentrasi Mass $\left(\mu \mathrm{g} / \mathrm{m}^{3}\right)$} & \multicolumn{3}{c}{ Rasio Komponen $/ P M_{2.5}(\%)$} \\
\cline { 2 - 7 } & 2011 & 2012 & 2013 & 2011 & 2012 & 2013 \\
\hline$B C$ & 2,52 & 1,92 & 2,19 & 15,86 & 16,60 & 17,72 \\
Sulfur & 2,896 & 1,93 & 1,94 & 18,22 & 16,67 & 15,7 \\
Garam Laut & 0,324 & 0,28 & 0,3 & 2,00 & 2,45 & 2,42 \\
Asap & 0,159 & 0,11 & 0,1 & 1,00 & 0,92 & 0,84 \\
Debu Tanah & 0,431 & 0,42 & 0,51 & 2,70 & 3,65 & 4,11 \\
Unsur minor & 0,27 & 0,26 & 0,33 & 1,70 & 2,71 & 2,67 \\
\hline RCM & 6,60 & 4,92 & 5,37 & $\mathrm{x}$ & $\mathrm{x}$ & $\mathrm{x}$ \\
$P M_{2.5}$ & 15,89 & 11,55 & 12,36 & $\mathrm{x}$ & $\mathrm{x}$ & $\mathrm{x}$ \\
Rasio RCM $/ P M_{2.5}$ & $\mathrm{x}$ & $\mathrm{x}$ & $\mathrm{x}$ & 41,54 & 42,60 & 43,45 \\
\hline
\end{tabular}

tidak termasuk konsentrasi massa karbon organik serta aerosol sekunder ammonium nitrat $\left(\mathrm{NH}_{4} \mathrm{NO}_{3}\right)$ karena fokus penelitian ini adalah untuk karakterisasi multi unsur. Rasio $R C M$ terhadap pengukuran konsentrasi massa $P M_{2.5}$ secara gravimetri pada tahun 2011-2013 berturut-turut sebesar $41.54,42.60$ dan 43.45\%. Hasil tersebut sesuai dengan kajian yang diberikan sebelumnya bahwa nilai total jumlah konsentrasi $R C M$ serta unsur-unsur minor merupakan hasil jumlah dari konsentrasi massa unsur-unsur logam $(\mathrm{Mn}, \mathrm{Cu}, \mathrm{Mg}, \mathrm{Zn}$, $\mathrm{Pb}$, dll) hanya sebesar $\pm 50 \%$ dari nilai pengukuran konsentrasi $P M_{2.5}[11]$.

\section{Karakterisasi reseptor model PMF untuk $\boldsymbol{P M}_{2.5}$}

Matrik data konsentrasi dan ketidakpastian digunakan sebagai input dari $P M F$. Pada Gambar 1(a) terlihat lima faktor kandungan emisi $P M_{2.5}$ yang berhasil dimodelkan oleh reseptor model. Pada faktor satu unsur timbal $(\mathrm{Pb})$ paling dominan $77 \%$ serta $\mathrm{Zn}$ sebesar $20.10 \%$ dibandingkan dengan faktor lainnya, oleh karena itu dapat diidentifikasikan faktor satu adalah berasal dari industri peleburan logam dalam hal ini adalah $\mathrm{Pb}$. Sedangkan kontribusi faktor satu terhadap fraksi $P M_{2.5}$ adalah sebesar $9.61 \%$ Gambar 1(b). Keberadaan unsur penanda Al, 
$\mathrm{Si}$, $\mathrm{Ti}, \mathrm{Ca}$ dan $\mathrm{Fe}$ di faktor dua mengidentifikasikan profil faktor tersebut berasal dari debu tanah. Konsentrasi Ca berasal dari aktivitas industri pembuatan konstruksi berbahan dasar beton [15]. Komposisi faktor debu tanah didalam $P M_{2.5}$ adalah $10.44 \%$. Hasil yang didapatkan ini berbeda dengan studi yang dilakukan sebelumnya oleh Santoso pada tahun 2008 unutk periode sampling paparan singkat dimana komposisi debu tanah dalam $P M_{2.5}$ sebesar $17 \%$ [9].

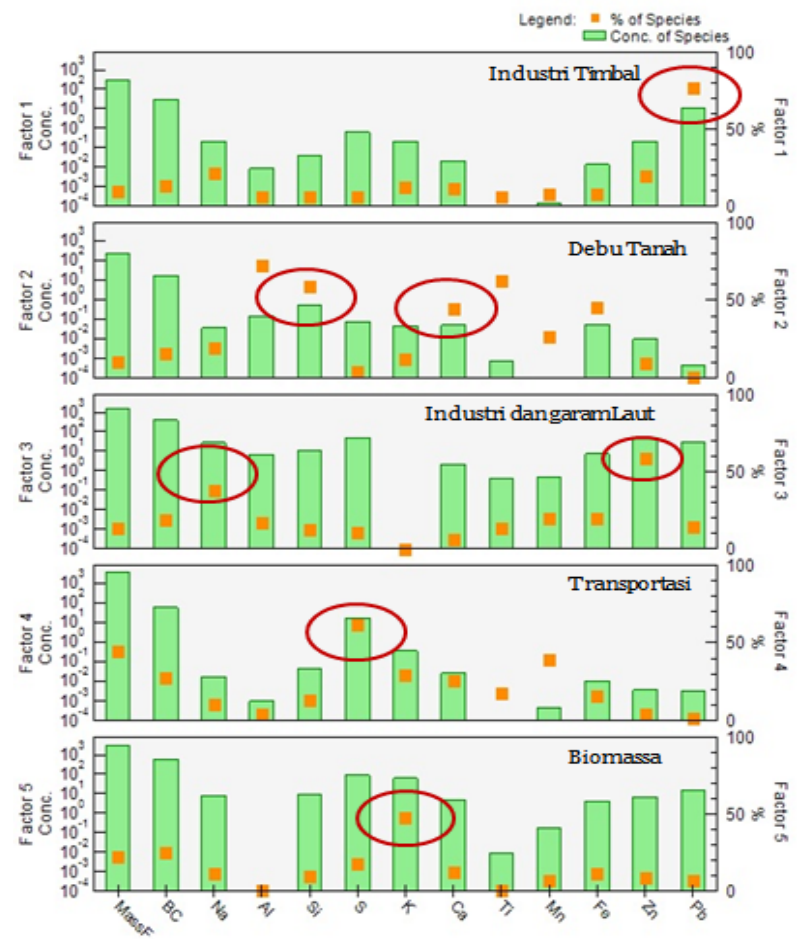

(a)
(28.78\%), Ca (25.28\%) dan BC (27.1\%). Unsur penanda tersebut sesuai dengan kajian sebelumnya yang berasal dari sektor transportasi serta pada umumnya adalah dari emisi sekunder kendaraan bermotor berbahan bakar bensin dan diesel [16]. Kontribusi profil transportasi bagi fraksi $P M_{2.5}$ adalah sebesar $44.36 \%$. Faktor lima dengan unsur penanda $\mathrm{K}(47.43 \%)$ serta $B C$ (25.28\%) merupakan profil dari pembakaran biomassa yang memberi kontribusi bagi $P M_{2.5}$ sebesar $22.58 \%$.

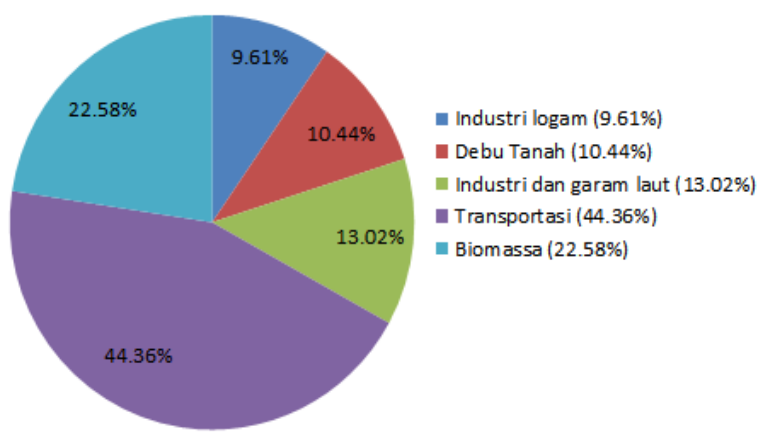

(b)

Gambar 4. Komposisi unsur pada setiap faktor (a), Kontribusi faktor terhadap $P M_{2.5}$ (b)

Pada faktor tiga dominasi unsur $\mathrm{Zn}$ (58.23\%), $B C$ (18.49\%) dan $\mathrm{Pb}$ (14.24\%) menandakan profil faktor tiga berasal dari profil industri logam. Sedangkan keberadaaan unsur penanda $\mathrm{Na}$ sebesar $38 \%$ memberi kesimpulan pada faktor tiga terdapat campuran sumber emisi lain yaitu dari profil butiran garam laut [11]. Faktor tiga ini memberi kontribusi $13.2 \%$ pada $P M_{2.5}$. Faktor keempat dengan unsur-unsur penanda S (61.76\%), Mn (39.17\%), K

\section{Estimasi lokasi sumber emisi}

Lima faktor Source contribution dari $P M F$ kemudian dianalisis berdasarkan data meteorologi arah dan kecepatan angin untuk mengestimasikan lokasi sumber pencemar $P M$. Hasil tersebut berupa grafik plot radar yang menggunakan 16 arah mata angin sebagai prediksi arah dari sumber pencemar. Land mark berwarna biru merupakan batas kajian estimasi terjauh dengan jarak $20 \mathrm{Km}$ dari titik sampling sedangkan yang 
berwarna merah merupakan daerah lokasi survey sumber pencemar $P M$. Hasil overlay grafik plot radar $C P F$ didalam peta terlihat pada Gambar 5. Pada profil satu estimasi lokasi dengan nilai $C P F$ tertinggi untuk sumber emisi peleburan logam $\mathrm{Pb}$ berasal dari arah barat daya hingga Barat Barat Laut wilayah kecamatan Parung Panjang, Bogor. Hasil tersebut sesuai dengan kajian pada tahun 2008 yang menyatakan bahwa estimasi lokasi sumber pencemar logam berat $\mathrm{Pb}$ daerah Serpong berasal dari kegiatan peleburan aki bekas yang berada pada arah barat daya Serpong [9]. Estimasi lokasi faktor tiga dari arah Barat Laut (Curug Tangerang) dan Barat Laut (Jati Uwung, Tangerang) dan Utara merupakan daerah kawasan industri di Tangerang. Arah utara faktor tiga juga merupakan arah dari emisi garam laut karena berdekatan dengan laut jawa namun dapat dimungkinkan emisi garam laut bercampur dengan emisi dari sektor transportasi karena arah Utara merupakan jalan raya serpong menuju gerbang tol Jakarta-Tangerang-Merak dimana kepadatan kendaraan bermotor terkonsentrasi di wilayah ini.

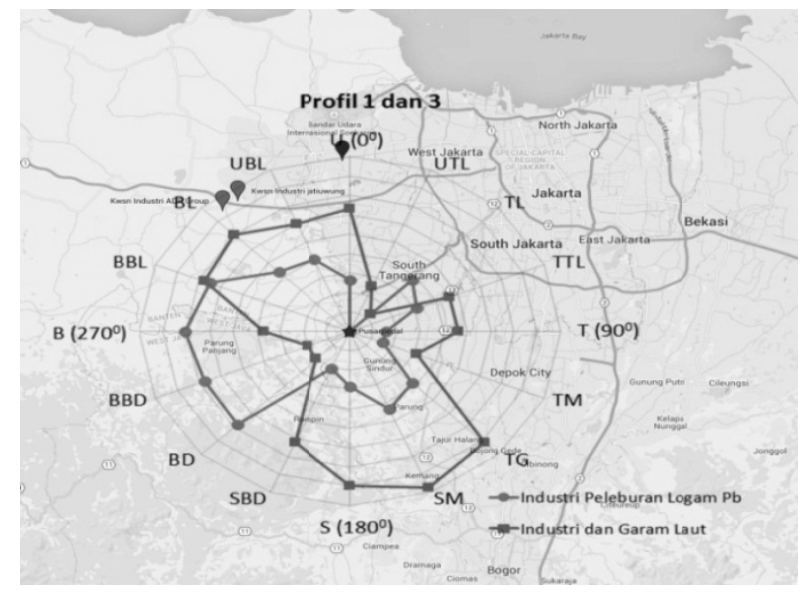

Gambar 5. Estimasi lokasi sumber pencemar pada profil 1 dan 3

Profil debu tanah Gambar 6 yang dominan berasal dari arah Timur Laut sampai dengan Timur Menanggara yang disebabkan oleh kegiatan alih fungsi lahan. Pengembangan kawasan perumahan di
Pamulang, Cisauk, Serpong Timur dan Serpong Utara, pengembangan dan pelebaran fasilitas jalan raya di daerah Pamulang serta pembangunan jalan tol lingkar luar Jakarta 2 (JORR2) yang menghubungkan daerah Ulujami-KunciranBandara Soekarno Hatta merupakan lokasi penyumbang kontribusi partikulat debu tanah pada faktor dua. Kegiatan industri pembuatan beton sebagai bahan konstruksi bangunan yang emisi debu tanah di Kecamatan Setu dan Cisauk turut berdampak terhadap kualitas $P M$ di udara. Emisi udara dari sektor transportasi (Gambar 7) disebabkan lokasi-lokasi tersebut merupakan titik rawan kemacetan seperti dari arah Utara yaitu Jalan raya Serpong, Jalan Kh. Hasim Ashari Kecamatan Cipondoh, gerbang pintu tol Jakarta-Merak, perempatan Cikokol perempatan lampu merah Alam Sutra Serpong, pasar Ciputat dan pintu tol Bintaro dari arah Timur laut, perempatan Pamulang dari sisi sebelah Timur. Hal yang sama dari arah Selatan dan tenggara yaitu pertigaan Perumpung dan perempatan Parung dimana lokasi tersebut adalah merupakan lokasi sumber emisi yang berasal dari transportasi.

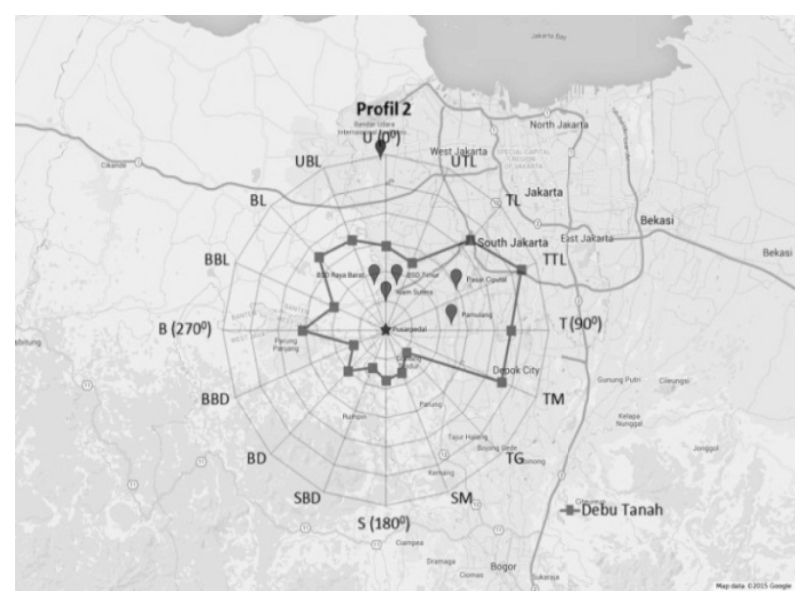

Gambar 6. Estimasi lokasi sumber pencemar pada profil 2

Pembakaran biomassa umumnya berasal dari kegiatan pembakaran jerami, ilalang maupun semak. Terlihat pada Gambar 8 bahwa emisi pembakaran 
biomassa yang ditangkap pada lokasi sampling dominan berasal dari daerah lain yaitu Kecamatan Parung Panjang yang wilayahnya masih banyak area persawahan dan kebun yang dimungkinkan sebagai lokasi asal partikulat biomassa. Penggunaan kayu sebagai bahan bakar untuk memasak terutama ketika kegiatan pesta pernikahan, sunatan, maupun kegiatan lainnya yang mengundang khalayak ramai. Kasus kebakaran yang meningkat sejak tahun 2011-2013 di wilayah yang padat penduduk yaitu kecamatan pondok Aren, Ciputat, Ciputat Timur dan Pamulang [17] turut memberi kontribusi terhadap emisi partikulat biomassa.

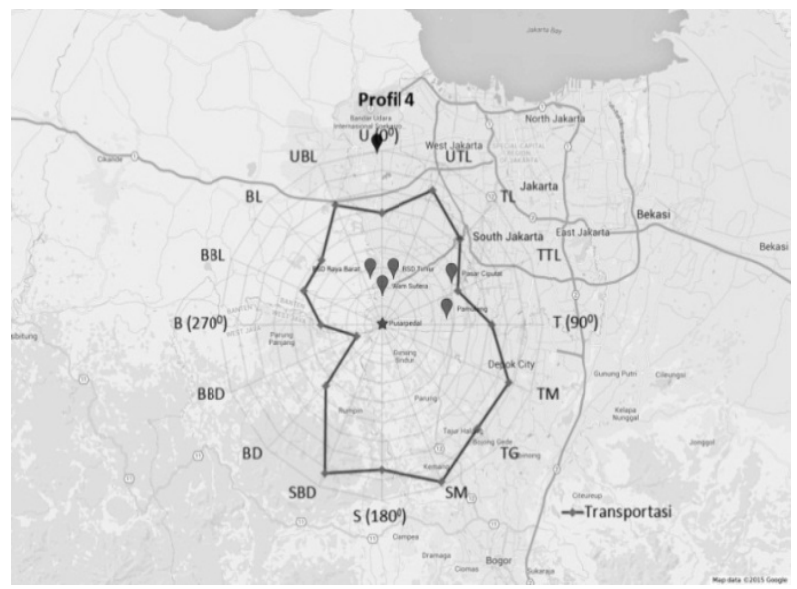

Gambar 7. Estimasi lokasi sumber pencemar pada profil 4

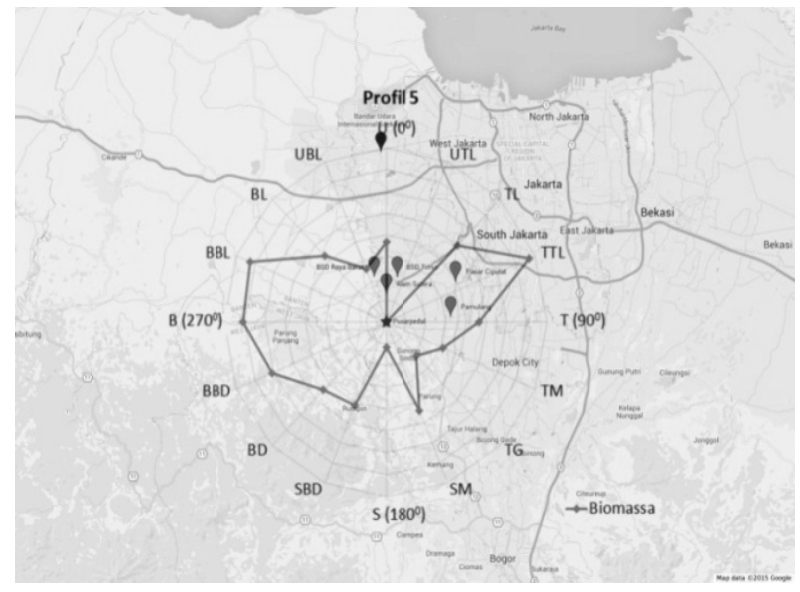

Gambar 8. Estimasi lokasi sumber pencemar pada profil 5

\section{KESIMPULAN}

Kajian mengenai identifikasi, karakterisasi serta estimasi lokasi sumber pencemar $P M$ di Kota tangerang Selatan menghasilkan pola konsentrasi massa ratarata $P M$ yang menurun periode 2011-2013. Penurunan konsentrasi massa tersebut kemungkinan karena faktor iklim yang lebih basah di tahun 2012 dan 2013, pembangunan TPST 3R serta kebijakan maupun peraturan yang dikeluarkan pemerintah mengenai pembatasan emisi gas buang kendaraan bermotor. Konsentrasi massa untuk $P M_{2.5}$ dan $P M_{10}$ pada periode 2011-2013 baik itu dalam bentuk time series maupun rata-rata tahunan tidak ada yang melebihi nilai baku mutu nasional. Walaupun demikian kegiatan pemantauan dan evaluasi paramater $P M$ di udara ambien kota Tangerang Selatan tetap harus dilakukan karena merupakan bagian dari pengendalian kualitas pencemaran udara.

Konsentrasi massa multi unsurhasil $X R F$ digunakan sebagai input dari reseptor model PMF 5.0 sehingga menghasilkan lima faktor sumber pencemar $P M$ yang terdiri dari Industri peleburan logam $\mathrm{Pb}$, debu tanah, campuran industri dan garam laut, transportasi serta pembakaran tidak sempurna biomassa. Persentase komposisi faktor sumber pencemar terbesaremisi $P M_{2.5}$ adalah dari transportasi kemudian faktor biomassa, campuran industri dan garam laut, debu tanah, dan industri peleburan logam.

\section{REKOMENDASI}

Berdasarkan Persentase komposisi faktor sumber pencemar terbesar emisi $P M_{2.5}$ adalah dari sektor transportasi maka sudah selayaknya Pemerintah kota Tangerang Selatan merumuskan suatu kebijakan serta tindakan untuk membatasi atau mengendalikan emisi gas buang kendaraan bermotor, sebagai contoh adalah mewajibkan pemilik kendaraan melakukan uji emisi kendaraan secara periodik, 
melakukan penghijauan disekitar titik rawan padat kendaraan dan sebagainya. Estimasi lokasi metode $C P F$ memberi hasil bahwa salah satu faktor sumber pencemar yaitu sektor industri berasal dari luar wilayah administrasi kota Tangerang Selatan sehingga diperlukan koordinasi yang komprehensif dan menyeluruh antar pemangku kebijakan maupun instansi terkait mengenai pemantauan dan evaluasi penyebaran pencemar $P M$ di lokasi sumber pencemar.

\section{UCAPAN TERIMA KASIH}

Penulis mengucapkan terima kasih pada rekan-rekan Bidang Senyawa Bertanda dan Radiometri PSTNT BATAN dan Bidang Keselamatan PAIR BATAN yang telah membantu preparasi sampel dan analisis data penelitian ini.

\section{DAFTAR PUSTAKA}

1. DOCKERY DW, POPE CA, XU X, SPENGLER JD, WARE JH, FAY ME, FERRIS BG, SPEIZER FE, An association between air pollution and mortality in six US cities, New England Journal of Medicine, 329, 1753 - 1759 (1993).

2. MÖLTER $M$, AGIUS RM, VOCHT $F$, LINDLEY S, GERRARD W, LOWE L, BELGRAVE D, CUSTOVIC A, SIMPSON A., Long-term exposure to $\mathrm{PM}_{10}$ and $\mathrm{NO}_{2}$ in association with lung volume and airway resistance in the MAAS birth cohort, Environmental Health Perspectives, 10 (121), 1232-1238 (2010).

3. SAMET JM, ZEGER SL, DOMINICI F, CURRIERO $F$, COURSAC I,DOCKERY DW, SCHWARTZ J, ZANOBETTI A., The National morbidity, mortality, and air pollution study. part II: morbidity and mortality from air pollution in the United States, Research Reports of the Health Effects Institute. 94, 570 (2000).

4. DOCKERY DW, CUNNINGHAM J, DAMOKOSH AL, NEAS LM, SPENGLER JD, KOUTRAKIS P, WARE JH, RAIZENNE M, SPEIZER $\mathrm{FE}$, Health effects of acid aerosols on North American children: respiratory symptoms, Environmental health perspectives, 104, 500-505 (1996).

5. [WHO AQG] World Health Organization Air Quality Guidelines, Air quality guidelines for particulate matter, ozone, nitrogen dioxide and sulphur dioxide, Global update 2005. Summary of risk assessment, Geneva (2006).

6. [PP] Peraturan Pemerintah No 41 Tahun 1999 Tentang Pengendalian Pencemaran Udara, Jakarta (1999).

7. [EEA] European Environmental Agency, Air Quality in Europe - 2013 report. Copenhagen (Denmark), European Environment Agency report (2013).

8. HOPKE PK, COHEN DD, BEGUM BA, BISWAS SK, BANGFA N, PANDIT GG，SANTOSO M, CHUNG YS, DAVY P, ANDREAS MARKWITZ A, et al., Urban air quality in the Asian region, Science of Total Environment, 404, 103-112 (2008).

9. SANTOSO $\mathrm{M}$, LESTIANI DD, MUKHTAR R, HAMONANGAN E, SYAFRUL $\mathrm{H}, \quad$ ANDREAS MARKWITZ A, HOPKE PK., Preliminary study of the sources of ambient air pollution in Serpong, Indonesia, Atmospheric Pollution Research, 2 (2011), 190-196 (2011).

10. MUKHTAR $R$, HAMONANGAN $E$, WAHYUDI $\mathrm{H}$, SANTOSO $\mathrm{M}$, 
KURNIAWATI S., Komponen Kimia $P M_{2.5}$ dan $P M_{10}$ di Udara Ambien Serpong-Tangerang, Ecolab. Vol 7 (1), 1-7 (2013).

11. COHEN D. Notes for IAEA Fingerprinting, Source Apportioment of Air Pollution Workshop CIAE, Beijing, China (2005).

12. HOPKE PK., A guide to positive matrix factorization, EPA Workshop Proceedings Materials from the Workshop on UNMIX and PMF as Applied to PM2.5 (2000).

13. DE BRUIN $\mathrm{Y}$, KOISTINEN $\mathrm{K}$, YLITUOMI $\mathrm{T}$, KEPHALOPOULOS $\mathrm{S}$, JANTUNEN M., A review of Source Apportionment Techniques Marker Substance Available for Identification of Personal Exposure, Indoor, and Outdoor Sources of Chemical, European Commission Directorate-General Joint Research Centre, Italy (2006).

14. KHILLARE PS AND SARKAR S., Airborne inhalable metals in residential areas of Delhi, India: distribution, source apportionment and health risks, Atmospheric Pollution Research, 3, 46-54 (2012).

15. LI et.al dalam Gugamsetty $B$, Wei $H$, Liu CN, Awasthi A, Hsu SC,Tsai CJ, Roam GD, Wu YC, Chen CF2, Source Characterization and Apportionment of PM10, PM2.5 and PM0.1 by Using Positive Matrix Factorization, Aerosol and Air Quality Research, 12, 476-491 (2012).

16. NORBECK JM, DURBIN TD, TRUEX TJ., Measurement of Primary Particulate Matter Emissions from Light-Duty Motor Vehicles Final Report, CRC Project No. E-24-2. University of California, USA (1998).

17. PERMANA, Evaluasi Keandalan Sistem Keselamatan Kebakaran Bangunan dengan Menggunakan Pedoman Pemeriksaan Keselamatan Kebakaran Bangunan Gedung (PdT-11-2005-C) di RSUD Kota Tangerang Selatan Tahun 2014 [Skripsi], Jakarta Selatan (ID): Universitas Islam Nasional Syarif Hidayatullah Jakarta (2014). 